\title{
Evaluating SEBAL for estimating arid zone shallow groundwater discharge.
}

\author{
Vjeko Matic $^{\mathrm{a}}$, Justin, F., Costelloe ${ }^{\mathrm{a}}$, Andrew, W., Western ${ }^{\mathrm{a}}$, Jeffery, P., Walker ${ }^{\mathrm{b}}$ and Scott, W., Tyler . $^{\mathrm{c}}$ \\ a Department of Infrastructure Engineering, The University of Melbourne, Victoria, Australia \\ b. Department of Civil Environmental Engineering, Monash University, Victoria, Australia \\ c Department of Geological Sciences and Engineering, University of Nevada, Reno, Nevada, USA \\ Email:vjmatic@gmail.com
}

\begin{abstract}
Shallow groundwater discharge in arid environments and subsequent loss by evapotranspiration (ET) often represents a significant component of the water balance. Evaporation is most reliably measured at the point scale. However, due to the vast distances over which this process can occur, field measurements of discharge are not viable. Remote sensing offers potential in mapping surface information which can be used to estimate ET. Various models have been developed to estimate ET from remote sensing imagery, though these have largely been applied to agricultural areas. Two studies, Kampf \& Tyler (2006) and Bastiaansen et al. (1998a,b), have applied a surface energy balance modelling approach for estimating ET using multispectral satellite imagery. The two studies have conflicting conclusions, with the Bastiaanssen et al. study claiming such an approach could provide useful estimates. The Kampf \& Tyler study suggested that the uncertainty within the model well exceeded the acceptable error margin of $50 \mathrm{~W} / \mathrm{m}^{2}$. Both studies tested their methods in an arid groundwater discharge zone though the landforms were slightly different. In this study, we employ eddy covariance instrumentation to obtain field measurements of the surface energy balance to apply the more rigorous validation method used by Kampf \& Tyler (2006). We use these data to test the Surface Energy Balance for Land Algorithm (SEBAL) which was developed and validated by Bastiaanssen et al. (1998a,b), by applying it to the Landsat 5 data on groundwater discharge zones along the margin of the Great Artesian Basin (Figure 1). SEBAL is a widely used algorithm, but has mainly been tested in agricultural settings. Our results show that the model structure is seriously limited in its application in this environment. SEBAL is not able to adequately represent the Bowen ratio, which it assumes is related to the surface temperature. As a result, we see the spatial distribution of latent energy (LE) flux estimates being controlled by net radiation. Applying SEBAL to a summer image where the surface temperature appears to be strongly related to the Bowen Ratio, we see that SEBAL performs much better at representing the spatial distribution of LE fluxes. However, the uncertainty is very large in the net radiation calculations and when considering the low LE fluxes, this is significant. Further more, it remains to be investigated if the low surface temperature found in the discharge zones is caused by evaporative cooling or a high albedo.
\end{abstract}
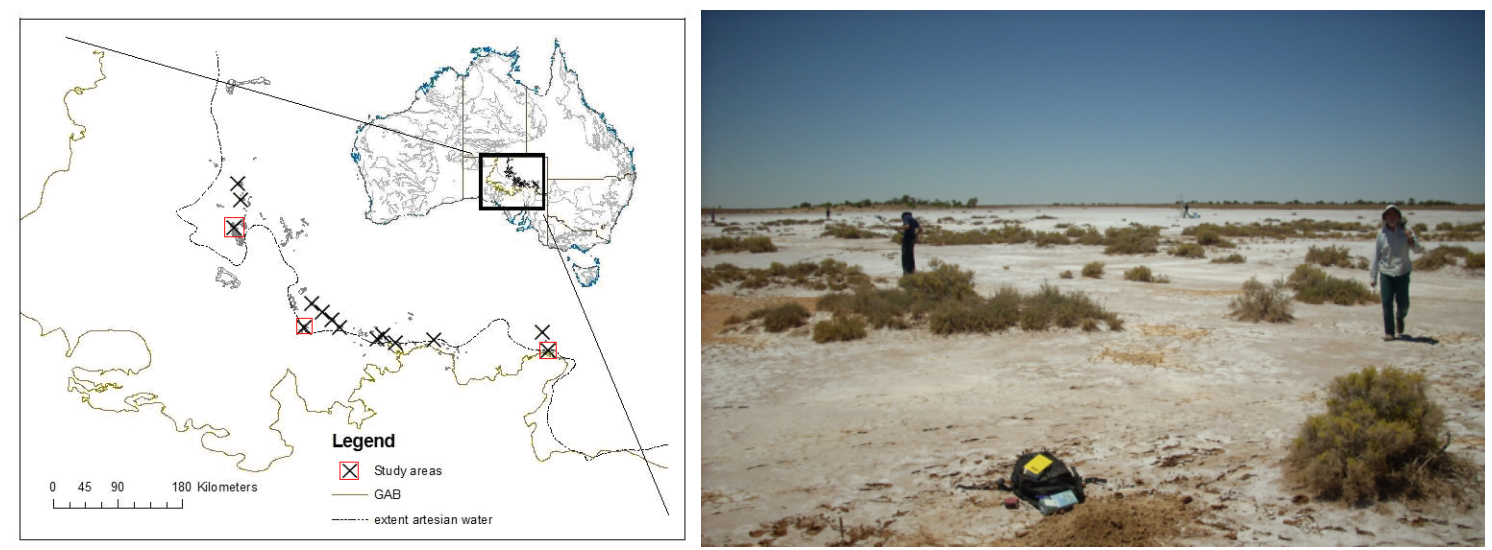

Figure 1 - Nilpinna discharge zone. Eddy covariance station (red box) was installed on a salt crusted section of the discharge zone.

Keywords: $\quad$ SEBAL, Arid, Shallow groundwater discharge. 


\section{INTRODUCTION}

Surface energy balance models typically will represent the various components of the surface energy balance using reflectance and radiative information from multispectral data. These data are used to represent parameters such as albedo, temperature and NDVI that then become the inputs into the surface energy balance model. Multispectral sensors with spatial resolution between $10-40 \mathrm{~m}$ in the optical wavelengths provide information at the scale needed to characterise evaporative processes, and adequately measure the spatial variation of shallow ground water discharge, which is often a heterogeneous process (Menenti et al, 1989; Tyler et al, 1997). Only studies by Baastiaanssen et al. (1998a) and Tyler \& Kampf (2006) have applied a remote sensing based approach for ET estimates in the specific environmental setting of shallow groundwater discharge in an arid environment. Kampf and Tyler (2006) tested an approach at the Salar de Atacama in Chile, which is a high altitude playa (groundwater discharging salt lake). Their results suggest the approach is limited, largely due to the extremely low latent heat flux rates generally associated with groundwater discharge associated with this process. These fluxes are rarely above $\sim 70 \mathrm{~W} / \mathrm{m}^{2}$, and often below the acceptable error margin of these algorithms of $50 \mathrm{~W} / \mathrm{m}^{2}$ (Kampf \& Tyler, 2006). The Surface Energy Balance for Land Algorithm (SEBAL), developed by Bastiaanssen et al. (1998a), is a widely used model (Tasumi, 2000; Timmermans 2007), and used primarily in agricultural areas. However, SEBAL was developed using field data from a similar arid area shallow groundwater discharge environment (Quattar depression, Western Egypt) as the basis for some of the empirical relationships on which the algorithm is based. SEBAL was also validated in the Quattar depression (Bastiaanssen et al, 1998b) with reportedly promising results in terms of expected latent energy (LE) fluxes over the entire study area. At the Quattar Depression, SEBAL was validated using a hydrogeological model where evaporative discharge was assumed to be the only discharge mechanism and therefore LE fluxes should equal estimated recharge. However, this validation method would presumably feature a large uncertainty in the recharge estimate and it is incapable of assessing at what degrees of accuracy the various components of the surface energy balance are being represented. The Kampf and Tyler (2006) study used field based eddy covariance instruments at a number of locations to represent the spatial variation of surface energy balance partitioning. With these data they were able to systematically assess which components of the surface energy balance were associated with the highest uncertainty. They were also able to characterise the surface energy balance over different landforms associated with the process, and investigate how their surface energy balance model was performing comparatively over the different landforms.

Our study aims to assess the potential in deriving continuous field discharge estimates along the south-west margin of the Great Artesian Basin (GAB) from multispectral remote sensing imagery using SEBAL, and using eddy covariance data to gauge uncertainty associated with this method (Figure 1).

\section{METHODS}

\subsection{Study area}

The Nilpinna discharge zone is part of the southwestern margin of the Great Artesian Basin in South Australia (Figure 1). The entire discharge area is approximately $40 \mathrm{~km}$ long, running north-south, to the west of the Peak-Denison Ranges. West of the discharge area is characterised by a homogeneous gibber plain for many tens of kilometres. The gibber plain is characterised by a desert pavement consisting of ferrous ironstone lag. The gibber features little to no vegetation, except for along drainage depressions where some salt bush and grasses occur. Directly to the east, and the southeast lies a sand dune field, and further east the outcropping basement rock of the Peake-Denison ranges.

\subsection{Field measurements}

Eddy covariance data were collected at Nilpinna from the $9^{\text {th }}-17^{\text {th }}$ of November 2008 and estimated LE fluxes using the Licor gas analyser and sonic anemometer; the latter is used to collect wind speed and 3D direction (eddy currents). Soil heat flux plates were used to estimate the soil heat flux. A meteorological station measured relative humidity and air temperature at approximately $2 \mathrm{~m}$ above the surface. A four-way radiometer was used to measure net radiation. The eddy covariance station was installed on salt flats that represent the landforms associated with the shallowest water tables and highest rates of discharge (Figure 1). The salt flats are typically characterised by high surface soil moisture and precipitated salt crusts. Raw eddy covariance data were then adjusted using the Bowen ratio method (Twine et al, 2000). This is a forced closure method which has been shown to result in the most accurate latent energy and sensible heat $(\mathrm{H})$ fluxes using equation (1). 
$\mathrm{Rn}-\mathrm{G}-\mathrm{LE}-\mathrm{H}=0$

Where $\mathrm{Rn}$ is the net radiation and $\mathrm{G}$ is the soil heat flux.

\subsection{SEBAL}

\section{Incoming solar radiation}

A Landsat 5 image on the $20^{\text {th }}$ of October 2008 (L5100080 08020081020) was used to test SEBAL at Nilpinna. The incoming solar radiation $\mathrm{R}_{\mathrm{s} \downarrow}$ is used to calculate the net shortwave radiation. No field data are required for this calculation.

$\mathrm{R}_{\mathrm{s} \downarrow}=\mathrm{G}_{\mathrm{sc}} \times \cos \theta \times \mathrm{d}_{\mathrm{r}} \times \tau_{\mathrm{sw}}$

$\mathrm{G}_{\mathrm{sc}}$ is the solar constant $\left(1367 \mathrm{~W} / \mathrm{m}^{2}\right), \cos \theta$ is the cosine of the solar incidence angle, $\mathrm{d}_{\mathrm{r}}$ is the inverse squared relative earth-sun distance, $\tau_{\mathrm{sw}}$ is the atmospheric transmissivity. The atmospheric transmissivity is calculated using equation 3.

$\tau_{\mathrm{sw}}=0.75+2 \times 10^{-5} \times \mathrm{z}$

Where $\mathrm{z}$ is the elevation in meters above sea level. The net solar radiation $\mathrm{R}_{\mathrm{s}_{-} \text {net }}$ is calculated using equation 4.

$\mathrm{R}_{\mathrm{s}_{-} \text {net }}=(1-\alpha) \mathrm{R}_{\mathrm{S} \downarrow}$

Where $\alpha$ is the albedo.We run SEBAL using equation 5 (Liang et al 2002), since the default SEBAL albedo $(\alpha)$ estimates where significantly over estimated.

$\alpha=0.356 \alpha 1+0.13 \alpha 3+0.373 \alpha 4+0.085 \alpha 5+0.071 \alpha 7$

Where the albedo of each band is the calculated reflectance. Outgoing longwave radiation $\left(\mathrm{R}_{\mathrm{L} \uparrow}\right)$ is calculated using equation 6 .

$\mathrm{R}_{\mathrm{L} \uparrow}=\varepsilon_{\mathrm{o}} \times \sigma \times \mathrm{T}_{\mathrm{s}}^{4}$

Where $\varepsilon_{\mathrm{o},}$ is the dimensionless "broad band" surface emissivity, $\sigma$ is the Stefan-Boltzmann constant $(5.67 \times$ $10 \mathrm{~W} / \mathrm{m} / \mathrm{K})$, Ts is the surface temperature estimated from the satellite imagery. The incoming longwave radiation $\left(\mathrm{R}_{\mathrm{L} \downarrow}\right)$ is calculated using equation 7 .

$\mathrm{R}_{\mathrm{L} \downarrow}=\varepsilon_{\mathrm{a}} \times \sigma \times \mathrm{T}_{\mathrm{a}}$

Where, $\varepsilon_{\mathrm{a}}$ is the atmospheric emissivity and $\mathrm{T}_{\mathrm{a}}$ is the air temperature derived from meteorological measurements. Following these steps SEBAL can then compute the net radiation. (Equation 8).

$\mathrm{R}_{\mathrm{n}}=(1-\alpha) \mathrm{R}_{\mathrm{S} \downarrow}+\mathrm{R}_{\mathrm{L} \downarrow}-\mathrm{R}_{\mathrm{L} \uparrow}-\left(1-\varepsilon_{\mathrm{o}}\right) \mathrm{R}_{\mathrm{L} \downarrow}$

Once net radiation is calculated, SEBAL calculates the remaining components of the surface energy balance. SEBAL calculates the soil heat flux as $0.4 x \mathrm{Rn}$. The soil heat flux as a factor of the net radiation which has been shown to be a fairly accurate representation (Bastiaanssen et al, 1998b).

\section{Sensible Heat Flux and Latent Heat Flux.}

The user next defines anchor point "hot"/ "dry" and "cold"/ "wet" pixels. The user then either defines the LE flux at the cold pixel, or allows SEBAL to estimate it. The sensible heat flux is then related to the surface temperature image using equation $\mathrm{x}$ and $\mathrm{y}$;

cold pixel dT; $\mathrm{dT}_{\text {cold }}=\mathrm{H}_{\text {cold }} \times \mathrm{r}_{\text {ah_cold }} /\left(\rho\right.$ cold $\left.\times \mathrm{c}_{\mathrm{p}}\right)$

hot pixel dT; $\mathrm{dT}_{\text {hot }}=\mathrm{H}_{\text {hot }} \times \mathrm{r}_{\text {ah_hot }} /\left(\rho\right.$ hot $\left.\times \mathrm{c}_{\mathrm{p}}\right)$

where $\mathrm{p}$ is the air density, $\mathrm{r}_{\mathrm{ah}}$ is the aerodynamic resistance to heat transport and $\mathrm{dT}$ is the difference between the surface temperature and air temperature. The latent energy fluxes are then taken as the residual of the surface energy balance (equation 1). 


\section{RESULTS}

\subsection{Field measurements}

The field measurements obtained from the eddy covariance data provide ranges of magnitudes for the daily energy fluxes. The measurements from the discharge zone show that almost all of the net radiation is used up in sensible heat fluxes (Figure 2, Table 1). We use an average of the first three days of eddy covariance measurements to obtain estimates for likely energy fluxes at $11 \mathrm{am}$, which coincides with the time of satellite overpass.

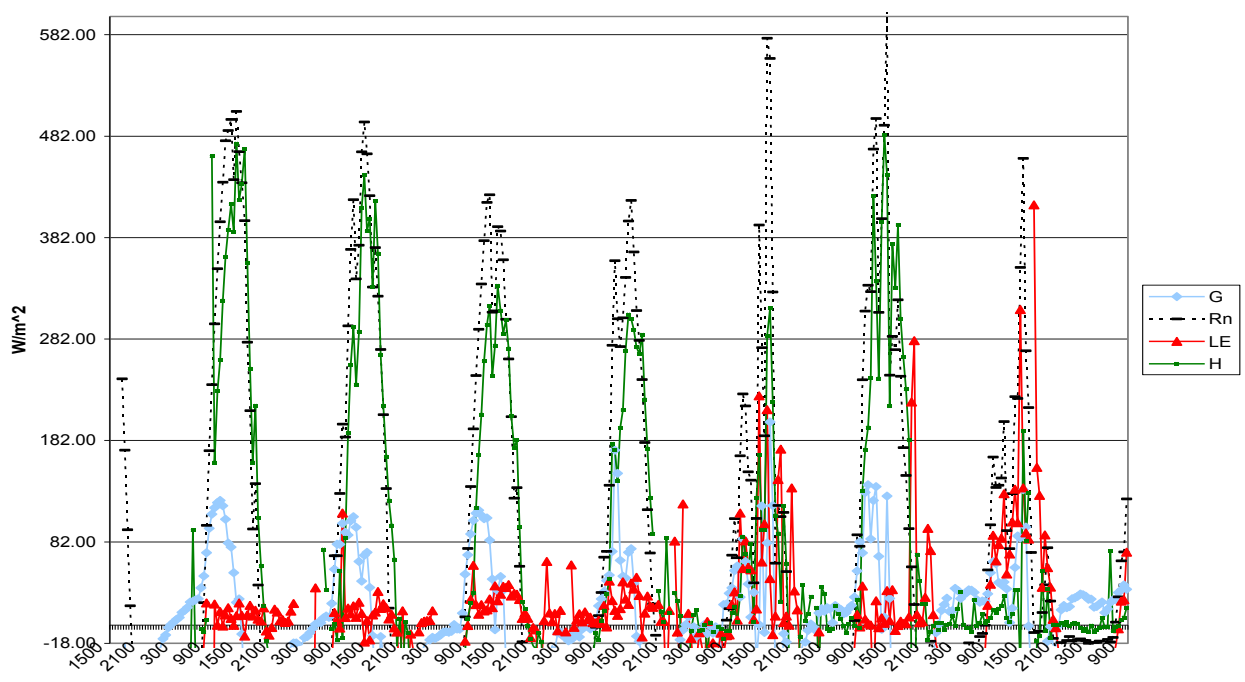

Figure 2 - Field measured surface energy balance. We see that the sensible heat fluxes account for most of the Rn. Latent heat fluxes are below $50 \mathrm{~W} / \mathrm{m}^{2}$ for the four days prior to rain fall $\left(10^{\text {th }}-13^{\text {th }}\right.$ October).

Table 1 - showing data collected at time of overpass and half an hour before and after. Averages are used for comparison to SEBAL results.

\begin{tabular}{|c|c|c|c|c|}
\hline & $\mathbf{L E}$ & $\mathbf{H}$ & $\mathbf{R n}$ & G \\
\hline $\begin{array}{l}10^{\text {th }} \text { October } \\
\text { (average) }\end{array}$ & 3.97 & 270 & 394 & 119 \\
\hline $10: 30$ & -0.11 & 230 & 351 & 120 \\
\hline 11:00 & 13 & 261 & 397 & 122 \\
\hline $11: 30$ & -0.97 & 319 & 436 & 117 \\
\hline $11^{\text {th }}$ October & 15 & 246 & 361 & 98 \\
\hline $10: 30$ & 17 & 189 & 294 & 88 \\
\hline 11:00 & 11 & 256 & 370 & 102 \\
\hline $11: 30$ & 18 & 293 & 419 & 106 \\
\hline $12^{\text {th }}$ October & 15 & 212 & 335 & 108 \\
\hline $10: 30$ & 11 & 168 & 292 & 113 \\
\hline 11:00 & 20 & 208 & 336 & 108 \\
\hline $11: 30$ & 14 & 260 & 379 & 105 \\
\hline Average & 11 & 242 & 365 & 108 \\
\hline
\end{tabular}




\subsection{Nilpinna SEBAL}
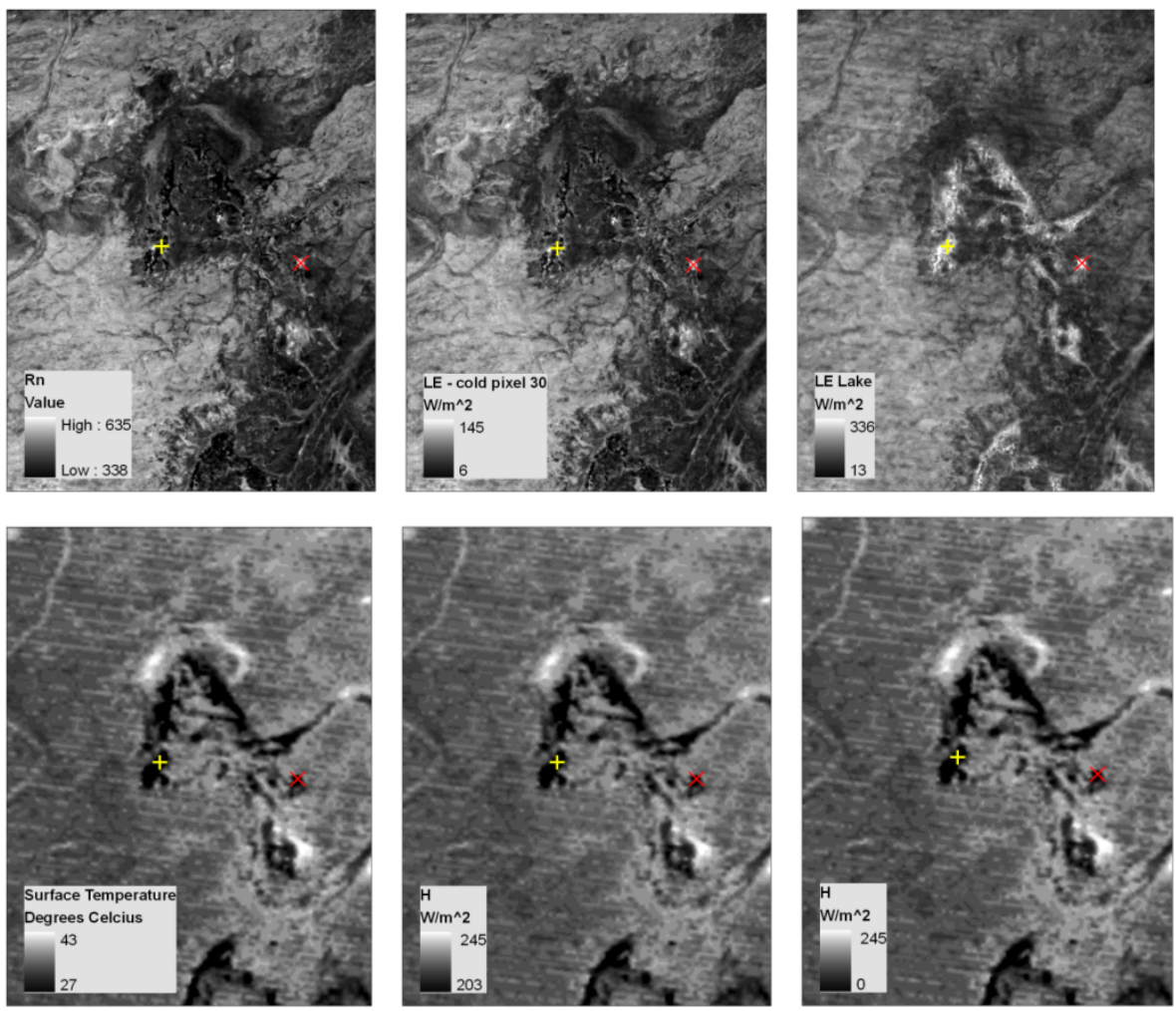

Figure 3. Nilpinna field area showing how LE and Rn have a very high spatial correlation. Using realistic estimates of LE (top middle) results in a small sensible heat flux gradient. A larger gradient still results in LE fluxes being controlled by $R \mathbf{n}(\mathrm{c})$.

The sensible heat flux does not vary much between the hot and cold pixels (Table 2). These two pixels define the range of the sensible heat flux and result in a small range of sensible heat flux over the entire image. Since LE is the residual, SEBAL appears to close the surface energy balance in high Rn areas by increasing LE fluxes, since there is no 'available' $H$. As a result, we see that the spatial distribution of LE fluxes is predominately controlled by Rn (Figure 3).

Table 2 shows how for a number of select pixels which represent the different landform in the study area, $H$ varies very little.

\begin{tabular}{lllll}
\hline $\mathrm{H}$ & LE & $\mathrm{Rn}$ & $\mathrm{G}$ & \\
\hline 213 & 40 & 427 & 170 & Nilpinna eddy modelled \\
223 & 83 & 515 & 204 & gibber 1 \\
244 & 13 & 434 & 173 & hot pixel \\
227 & 48 & 463 & 183 & vegetated terrace \\
223 & 89 & 524 & 208 & gibber 2 \\
\hline
\end{tabular}

\subsection{SEBAL January 2010}

Running SEBAL on a Landsat 5 image on a hot summer day in January we see that the surface temperature contrast between discharge and non-discharge areas is much higher (Figure 4). However, it is uncertain to what degree the low surface temperature is a product of evaporative cooling or due to a high albedo, or a combination of both. We use the MNDWI band ratio as a soil moisture index $(\mathrm{Xu}, 2006)$. We see that LE fluxes have a higher spatial correlation to albedo than the soil moisture index (Table 3). This may indicate that the high reflectance from the salt pans has a large effect on lowering the surface temperature. 

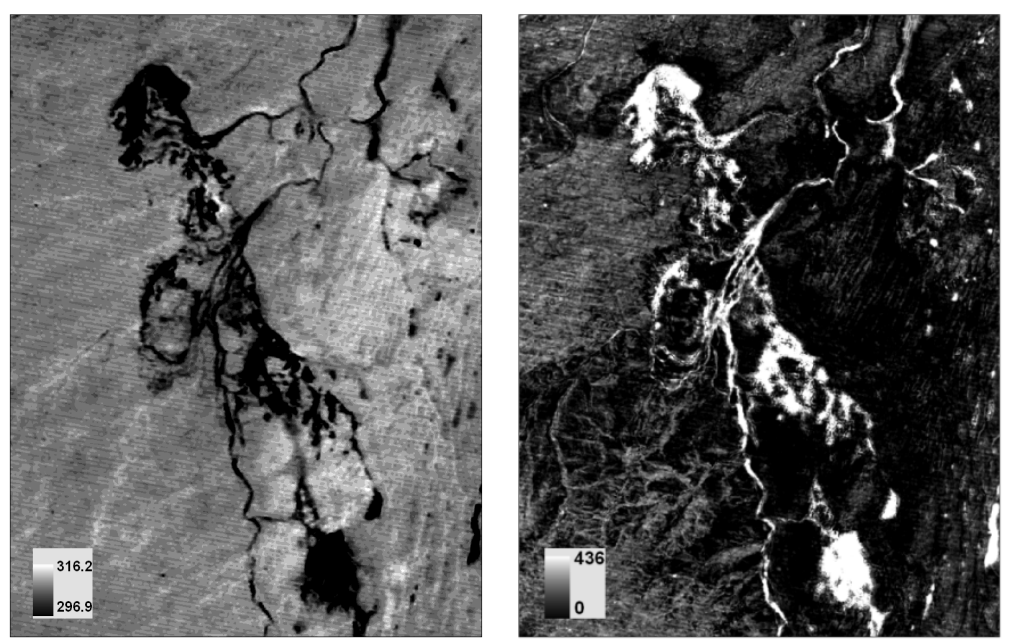

Figure 4 shows the summer image surface temperature image and LE flux distributions.

Table 3 Correlation between LE, albedo and Tsurf and MNDWI.

\begin{tabular}{|l|l|l|l|l|}
\hline & MNDWI & LE & Tsurf & Albedo \\
\hline MNDWI & 1.00 & 0.63 & -0.81 & 0.84 \\
\hline LE & 0.63 & 1.00 & -0.91 & 0.58 \\
\hline Tsurf & -0.81 & -0.91 & 1.00 & -0.87 \\
\hline Albedo & 0.84 & 0.58 & -0.87 & 1.00 \\
\hline
\end{tabular}

\subsection{Sensitivity analysis}

We adjusted some of the parameters and inputs based on variability found in field estimates. This allows us to explore the range of uncertainty in the net radiation value. Since SEBAL calculates LE fluxes as a residual term, we can assume that all the uncertainty in the net radiation is also found in all other flux estimates. Choosing two pixels (saline discharge zone and dry gibber plain), we see that $\mathrm{Rn}$ is highly sensitive to variability in the albedo (Figure 5). SEBAL is also relatively sensitive to air temperature estimates. The meteorological inputs are difficult to obtain with a suitable degree of certainty. These results show that when considering the low LE flux rates associated with shallow groundwater discharge, these uncertainties are significant.
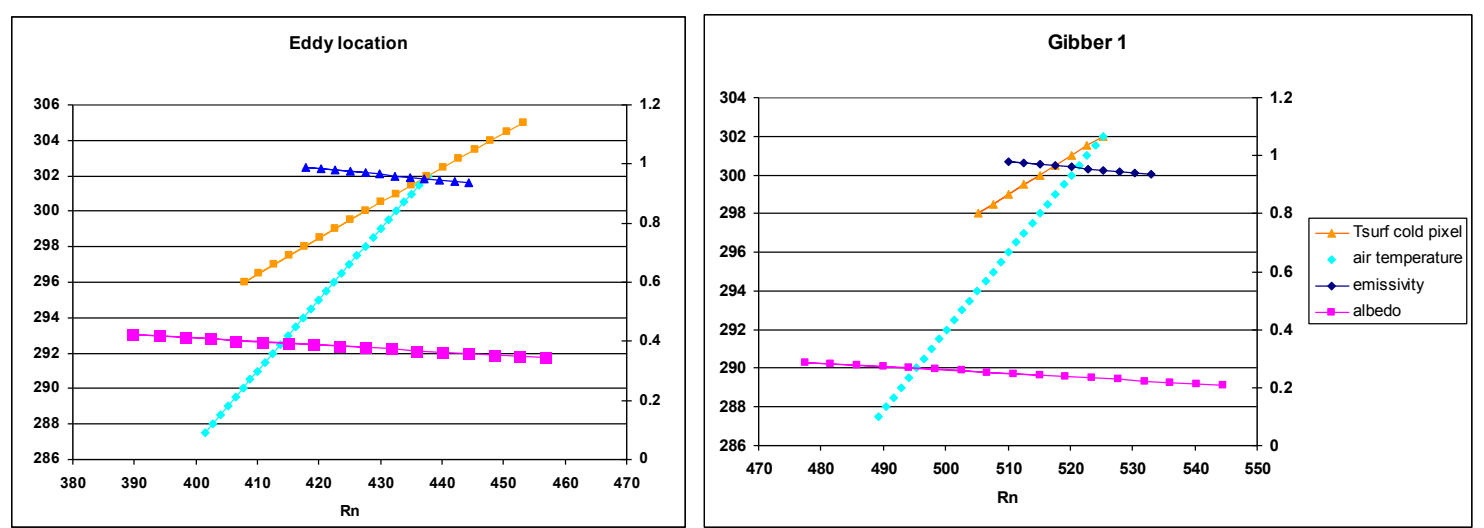

Figure 5 Sensitivity analysis results for parameters and inputs used to calculate $\mathrm{Rn}$ at the cold pixel, hot pixel and gibber and vegetated terrace. 


\section{DISCUSSION AND CONCLUSIONS}

The most important finding of this study is that SEBAL cannot estimate LE fluxes with sufficient accuracy in the arid zone environments of groundwater discharge zones along the margin of the GAB, though it can be used to represent the spatial distribution of LE fluxes. However, this can only be obtained from images acquired on hot summer days. We see from the October image (Figure 3) that without a strong temperature contrast between discharge and non-discharge zones, the SEBAL model structure falls apart and provides highly error-prone results. This is primarily due to an inability to adequately represent the Bowen ratio under such conditions. This poor partitioning of the Bowen Ratio is due to two things. The first is that due to the low LE fluxes at the wettest pixels, SEBAL is left with a very small sensible heat flux gradient between the cold and hot pixel. As a result, the sensible heat flux is not able to vary considerably. This forces SEBAL to close the surface energy balance by varying LE (since the LE flux is calculated as the residual) in pixels with high $\mathrm{Rn}$ values. This results in the LE flux distribution becoming primarily a function of the net radiation. Secondly, the model structure assumes that the surface temperature can be used to represent the Bowen Ratio. Therefore, it assumes that the surface temperature varies as a function of variation in LE fluxes. Whilst we see some relationship between LE fluxes and cold surface temperatures, there are other processes which control its distribution, such as albedo variations.

In the summer image, the spatial representation of the LE fluxes is more realistic. This is due to the temperature being very strongly correlated to discharge processes (LE fluxes). We also see that the LE fluxes are strongly correlated to a soil moisture index, which is qualitative support that the flux is being well represented. The albedo, surface temperature, LE fluxes and MNDWI are all highly correlated and it is not clear from this study if evaporative cooling or high solar radiation reflectance from the high albedo is responsible for the cool surface temperature in this zone. This should be further investigated.

Although SEBAL can represent the spatial extent of high LE fluxes, we see that there is a large degree of uncertainty in the inputs and parameters used to calculate Rn, and when compared to the low LE fluxes, these are significant.

\section{REFERENCES}

Bastiaanssen, W. G. M., Menenti, M., Feddes, R.A., Holtslag, A.A.M. (1998a). "A remote sensing surface energy budget algorithm for land (SEBAL). 1. Formulation." Journal of Hydrology 212 - 213(1-4): 213.

Bastiaanssen, W. G. M., Pelgrum, H., Wang, J., Ma, Y., Moreno, J.,Roerink, G. J., and van der Wal, T. (1998b). "The surface energy balance algorithm for land (SEBAL), Part 2: Validation." J. Hydrol., 212-213, $213-22$

Kampf, S. K., Tyler, S.W. (2006). "Spatial characterisation of land surface energy fluxes and uncertainty estimation at the Salar de Atacama, Northern Chile." Advances in Water Resources 29: 336- 354.

Liang, S., Fang, H., Chen, M., Shuey, C.J., Walthall, C., Daughtry, C., Morisette, J., Schaaf, C., and Strahler, A. (2002). Validating MODIS land surface reflectance and albedo products: methods and preliminary results. Remote Sensing of Environment, 83(1), 149-162.

Menenti, M., Bastiaanssen, W., van Eick, D., Abd el Karim, M.A. (1989). "Linear relationships between surface reflectance and temperature and their application to map actual evaporation of groundwater." Advances in Space Research 9(1): 165-176.

Tasumi M., Allen, R. G., \& Bastiaanssen, W. G. M. (2000). The theoretical basis of SEBAL. In A. Morse, M. Tasumi, R. G. Allen, \& W. Kramber (Eds.), Application of the SEBAL methodology for estimating consumptiveuse of water and streamflow depletion in the Bear River basin of Idaho through remote sensing. Final report to the Raytheon Systems Company, Earth Observation System Data and Information System Project. Idaho Department of Water Resources and University of Idaho, $107 \mathrm{pp}$

Twine, T., Kustas, W., Norman, J., Cook, D., Houser, P., Meyers, T., et al (2000). Correcting eddycovariance flux underestimates over a grassland. Agricultural and Forest Meteorology, 103, 279 - 300Wim J. Timmermans a , , William P. Kustas b, Martha C. Anderson, b, Andrew N. French (2007) An intercomparison of the Surface Energy Balance Algorithmfor Land (SEBAL) and the Two-Source Energy Balance (TSEB) modeling schemes . Remote Sensing of Environment 108 (2007) 369 - 38

$\mathrm{Xu}, \mathrm{H} ., 2006$. "Modification of normalised difference water index (NDWI) to enhance open water features in remotely sensed imagery", 273 International Journal of Remote sensing, vol. 27, no. 14, pp. 3025-3033 